\title{
Characterization of electromagnetic properties for durability performance and saturation in hardened cement mortar
}

\author{
Seung-Jun Kwon ${ }^{\mathrm{a}, *}$, Maria Q. Feng ${ }^{\mathrm{a}, 1}$, Sang Soon Park ${ }^{\mathrm{b}, 2}$ \\ ${ }^{a}$ Department of Civil E Environmental Engineering, University of California Irvine, Irvine, CA 92697, USA \\ ${ }^{\mathrm{b}}$ Korea Institute of Construction Materials, Seoul 137-707, Republic of Korea
}

\section{A R T I C L E I N F O}

\section{Article history:}

Received 26 March 2009

Received in revised form

10 September 2009

Accepted 14 September 2009

Available online 22 September 2009

Keywords:

Electromagnetic

Concrete

Diffusion

Porosity

Dielectric

\begin{abstract}
A B S T R A C T
Electromagnetic (EM) properties - dielectric constant and conductivity are changed with porosity and saturation in cement-based materials. In this paper, dielectric constant and conductivity are measured in cement mortar with 5 different mixture conditions considering saturation. For the same mixture proportions, durability tests including porosity, chloride diffusion, air permeability, sorptivity, and water diffusion are performed. Among the continuously measured EM properties within $5-20 \mathrm{GHz}$ of frequency range for different saturation, results under $60 \%$ of saturation which shows stable results are selected and averaged as one value. The averaged measurements utilizing results under $60 \%$ of saturation are compared with those from durability tests.

Through the normalization using the results of $\mathrm{W} / \mathrm{C} 40 \%$ which shows best durability performances, changing ratios of durability characteristics are evaluated with normalized dielectric constant and conductivity. The behaviors of EM properties with different saturation and their relationships with durability performances are studied.
\end{abstract}

Published by Elsevier Ltd.

\section{Introduction}

A non-destructive technique (NDT) is highly desirable for evaluating performance and condition of cement-based materials. Among the possible techniques, EM property-based NDT methods have been studied for these materials since they have unique EM properties of dielectric constant and conductivity in nonmetallic materials such as cement mortar and concrete [1,2]. The behaviors of EM properties have been studied in concrete with various mineral admixtures considering hydration process [3-9]. The studies on modeling for EM properties were also performed considering the porosity and saturation in concrete [10,11]. Assessment for deteriorated reinforcement concrete $(\mathrm{RC})$ structures were attempted using EM properties and their characterization [12-15]. Recently, NDTs utilizing EM properties were applied for detection of damaged area in concrete members retrofitted with composites [16-18]. Despite these research activities, very limited investigations have been performed on quantitative relationships between the EM properties and durability characteristics in cement-based construction materials. In hardened concrete, the pores and amount of hydrates have important role in both durability performance and reflection of EM

\footnotetext{
* Corresponding author. Tel.: +19495545454; fax: +19498249389.

E-mail addresses: seungjuk@uci.edu, jjuni98@yonsei.ac.kr (S.-J. Kwon). mfeng@uci.edu (M.Q. Feng), parkss87@kicm.re.kr (S.S. Park).

${ }^{1}$ Tel.: +19498242162; fax: +19498242117.

2 Tel.: +82 21232806 ; fax: +8221232806.
}

properties. The intrusion of harmful ion and transport of moisture are usually related with pores so that porosity in concrete can be utilized as an index for durability performance $[19,20]$. The mechanisms of ion diffusion, moisture transport, and permeability of liquid/gas are all affected by porosity. EM properties are most governed by moisture, so-called saturation, however, in dried condition, they are mainly affected by porosity and hydrates amount due to the effect of air on relative permittivity $[2,10]$.

The point aimed by this study is to evaluate the relationship between EM properties and durability characteristics considering porosity and saturation. Durability tests including compressive strength, porosity, chloride diffusion, air permeability, sorptivity and water diffusion are performed for specimens with different mixture conditions. The continuously measured data $(5-20 \mathrm{GHz}$ of frequency range) are averaged as one value and compared with saturation with time. Among averaged data, quantitative relationship for durability characteristics are derived through utilizing averaged EM properties under $60 \%$ of saturation. Furthermore, saturation effect on averaged EM properties is evaluated and discussed in this study.

\section{Experimental programs}

\subsection{Outline of tests}

In this test, ordinary Portland cement (OPC) mortar specimens with five water to cement $(\mathrm{W} / \mathrm{C})$ ratios are made and 
several tests are performed including porosity, chloride diffusion coefficient, permeability of air, sorptivity, and water diffusion coefficient. Table 1 shows the mix proportions including properties of sand.

\subsection{Tests for durability characteristics}

For evaluation of durability performances in cement mortar, several tests are prepared. Porosities in different curing periods (28 and 91days) are measured through mercury intrusion porosimetry (MIP) [21]. Compressive strength test is also performed based on the standard method [22]. Chloride diffusion coefficient is very important for an evaluation of service life or deterioration in RC structures exposed to chloride attack $[23,24]$. Based on the standard method-NT BUILD 492 [25], chloride diffusion coefficient in non-stationary condition is obtained. Three specimens per each mixture condition are prepared after 91 curing days. Based on the Darcy's Law, air permeability is obtained in mortar specimens with $10 \mathrm{~cm}$ of diameter and $3 \mathrm{~cm}$ of thickness [26]. Water diffusion coefficient [27] and related sorptivity [28] are also evaluated based on the references. These are considered as important parameters and closely related to porosity. Table 2 summarizes the tests performed in this paper.

Table 1

Mix proportions and properties of sand.

\begin{tabular}{|c|c|c|c|c|}
\hline $\mathrm{W} / \mathrm{C}(\%)$ & Cement $\left(\mathrm{kg} / \mathrm{m}^{3}\right)$ & Sand $\left(\mathrm{kg} / \mathrm{m}^{3}\right)$ & Water $\left(\mathrm{kg} / \mathrm{m}^{3}\right)$ & Flow $(\mathrm{cm})$ \\
\hline 40 & 390 & 1550 & 156 & 25 \\
\hline 45 & 390 & 1550 & 178 & 30 \\
\hline 50 & 390 & 1550 & 196 & 30 \\
\hline 55 & 390 & 1550 & 216 & 33 \\
\hline 60 & 390 & 1550 & 235 & 36 \\
\hline
\end{tabular}

Gravity $\left(=2.60 \mathrm{~g} / \mathrm{cm}^{3}\right)$, absorption (=0.95\%), fineness modulus (=2.64).

Weight of cement:sand $=1: 3.97$, siliceous sand (max. size: $4.75 \mathrm{~mm}$ ).

Table 2

Durability tests in this study.

\begin{tabular}{|c|c|c|}
\hline Items & Objectives and condition of samples & Related references \\
\hline Porosity & $\begin{array}{l}\text { - Porosity measurements } \\
\text { - curing age ( } 28 \text { and } 91 \text { days) }\end{array}$ & [21] \\
\hline Compressive strength & $\begin{array}{l}\text { - Strength evaluation } \\
\text { - curing age ( } 28 \text { and } 91 \text { days) }\end{array}$ & {$[22]$} \\
\hline Chloride diffusion test & $\begin{array}{l}\text { - Chloride diffusion coefficient through non-steady-state condition } \\
\text { - curing ages ( } 91 \text { days) }\end{array}$ & [25] \\
\hline Intrinsic permeability of air & $\begin{array}{l}\text { - Evaluation of air permeability based on Darcy's Law } \\
\text { - curing ages ( } 91 \text { days) }\end{array}$ & [26] \\
\hline Water sorptivity and diffusion & $\begin{array}{l}\text { - Water diffusion coefficient and sorptivity based on the Fourier series } \\
\text { - curing ages ( } 91 \text { days) }\end{array}$ & $\begin{array}{l}\text { - Water diffusion [27] } \\
\text { - water sorptivity [28] }\end{array}$ \\
\hline
\end{tabular}

a

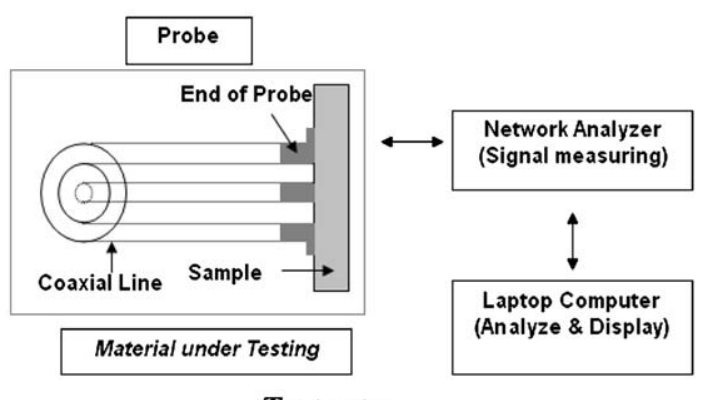

Test setup b

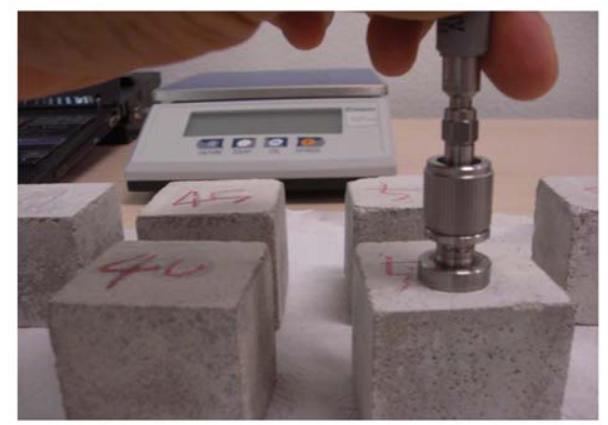

Measuring EM properties

Fig. 1. Test setup and measuring samples. 


\section{Measurement for EM properties with different saturation}

\subsection{Dielectric constant and conductivity}

In most common dielectric materials, relative permittivity can be expressed in Eq. (1), which consists of dielectric constant and loss factor $[2,18]$

$\varepsilon_{r}^{*}=\varepsilon_{r}^{\prime}-j \varepsilon^{\prime \prime} r$

where $\varepsilon^{*}{ }_{r}$ is the relative complex permittivity, and $\varepsilon^{\prime}{ }_{r}$ and $\varepsilon^{\prime \prime}{ }_{r}$ are its real and imaginary parts, respectively. The real part of the relative complex permittivity, so-called dielectric constant $\left(\varepsilon_{r}^{\prime}>1\right)$, means how much energy from an external electric field is stored in a material. The imaginary part of the relative complex permittivity $\left(\varepsilon^{\prime \prime}{ }_{r}>0\right)$, shows how dissipative the material is to an external electric field, which is simply referred to as the loss factor [2]. Another important parameter is known as equivalent conductivity which involves the imaginary part of the complex permittivity $\left(\varepsilon^{\prime \prime}\right)$ as follows:

$\sigma=\varepsilon^{\prime \prime} \omega=\left(\varepsilon^{\prime}{ }_{r} \varepsilon_{0} \tan \delta\right)(2 \pi f)$

where $\sigma$ is conductivity $(\mathrm{S} / \mathrm{m}), \omega$ is the wave angular frequency $(\mathrm{rad} / \mathrm{s}), \tan \delta$ is loss tangent (the ratio of energy lost to energy stored in a material) and $f$ is frequency in (Hz). These EM properties like dielectric constant and conductivity are not a

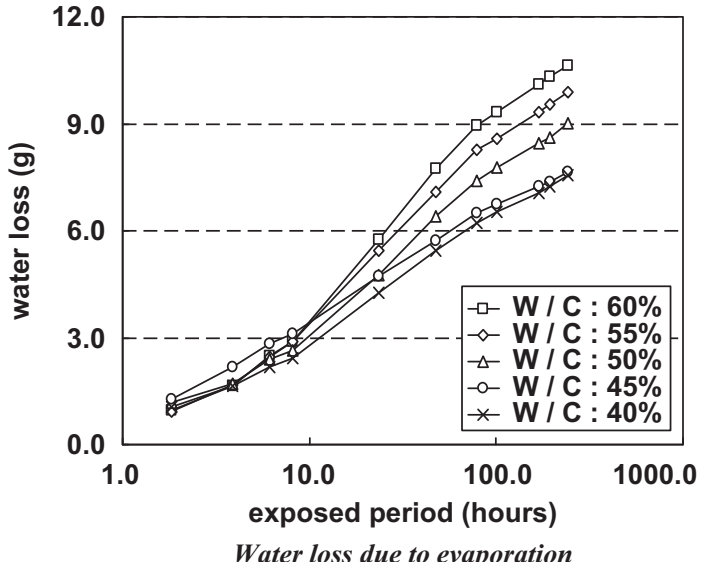

b

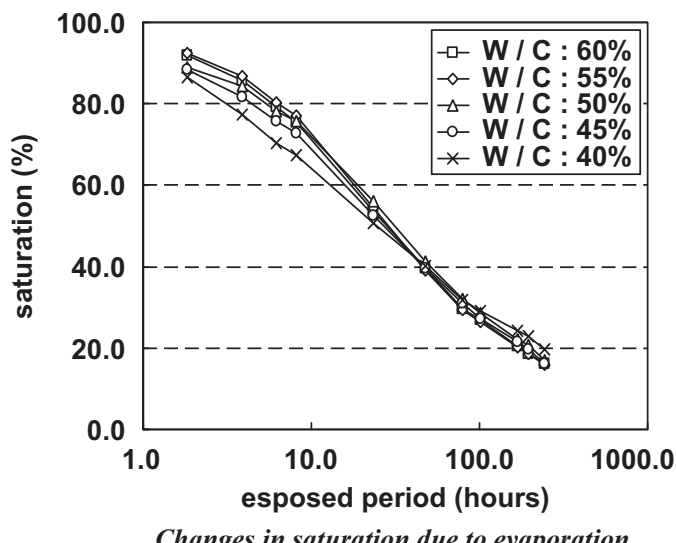

Fig. 2. Water loss and saturation with $\mathrm{W} / \mathrm{C}$ ratios.

a

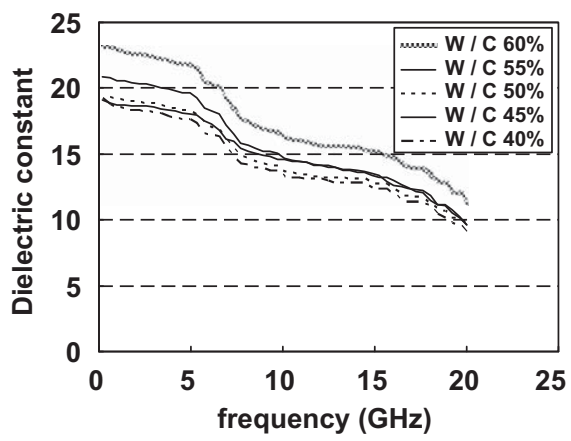

Dielectric constant (saturation 100\%)

C

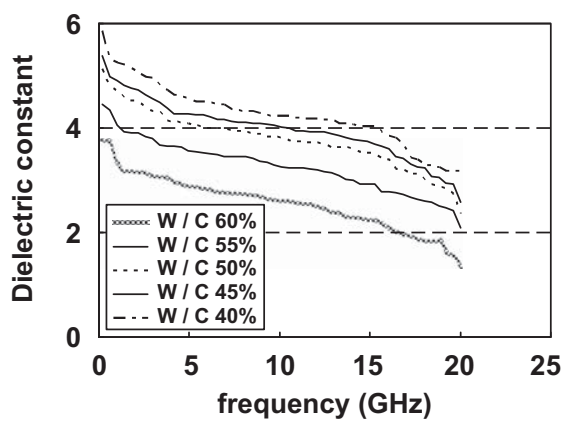

Dielectric constant (saturation 20\%) b

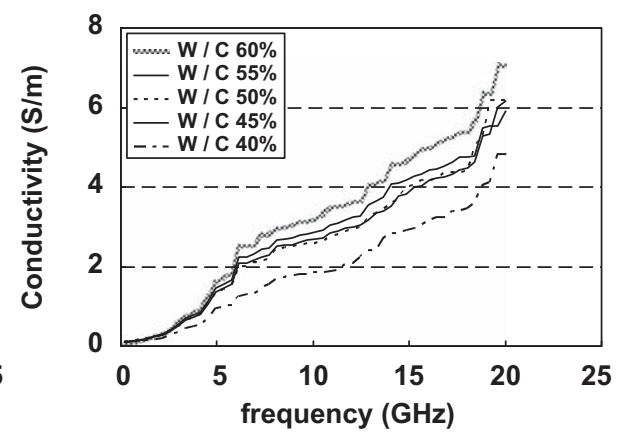

Conductivity (saturation 100\%)

d

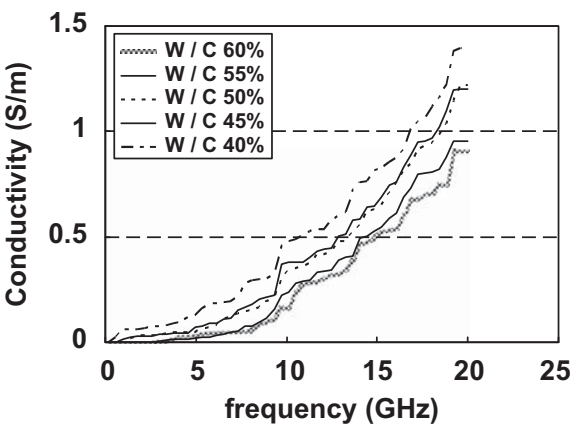

Conductivity (saturation 20\%)

Fig. 3. Measurement of EM properties with different saturation. 
Table 3

Regression results for dielectric constant and conductivity with saturation.

\begin{tabular}{|c|c|c|c|c|c|c|}
\hline \multicolumn{7}{|c|}{$E M=A \times(f)+B, f:$ frequency $(\mathrm{GHz})$} \\
\hline \multirow[t]{2}{*}{$\mathrm{W} / \mathrm{C}(\%)$} & \multicolumn{3}{|c|}{ Dielectric constant } & \multicolumn{3}{|c|}{ Conductivity (S/m) } \\
\hline & $A \times 10$ & $B$ & $\begin{array}{l}\text { Coefficient of } \\
\text { determination }\end{array}$ & $A \times 10$ & $B$ & $\begin{array}{l}\text { Coefficient of } \\
\text { determination }\end{array}$ \\
\hline \multicolumn{7}{|c|}{ Saturation $100 \%$} \\
\hline 60 & -5.92 & 23.55 & 0.96 & 3.22 & 0.00 & 0.98 \\
\hline 55 & -5.64 & 21.30 & 0.96 & 2.85 & 0.00 & 0.98 \\
\hline 50 & -5.02 & 19.77 & 0.95 & 2.61 & 0.00 & 0.97 \\
\hline 45 & -4.68 & 19.58 & 0.97 & 2.61 & 0.00 & 0.97 \\
\hline 40 & -4.87 & 19.15 & 0.96 & 1.92 & 0.00 & 0.96 \\
\hline \multicolumn{7}{|c|}{ Saturation $20 \%$} \\
\hline 60 & -0.87 & 3.45 & 0.95 & 0.33 & 0.00 & 0.80 \\
\hline 55 & -0.84 & 4.11 & 0.96 & 0.36 & 0.00 & 0.80 \\
\hline 50 & -0.91 & 4.70 & 0.93 & 0.45 & 0.00 & 0.83 \\
\hline 45 & -0.92 & 4.91 & 0.92 & 0.46 & 0.00 & 0.85 \\
\hline 40 & -0.98 & 5.24 & 0.92 & 0.55 & 0.00 & 0.90 \\
\hline
\end{tabular}

a

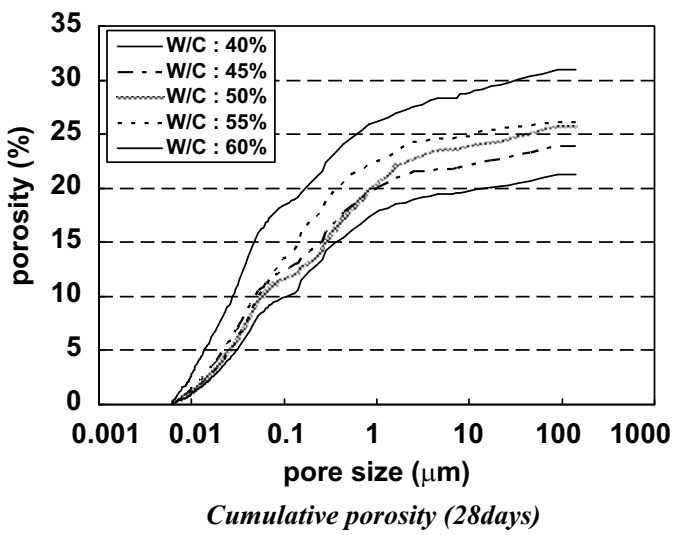

b

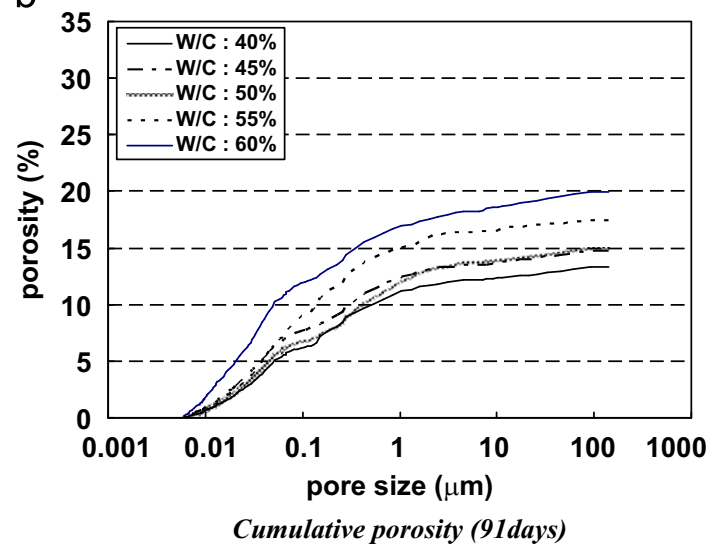

Fig. 4. Cumulative porosity measured through MIP.

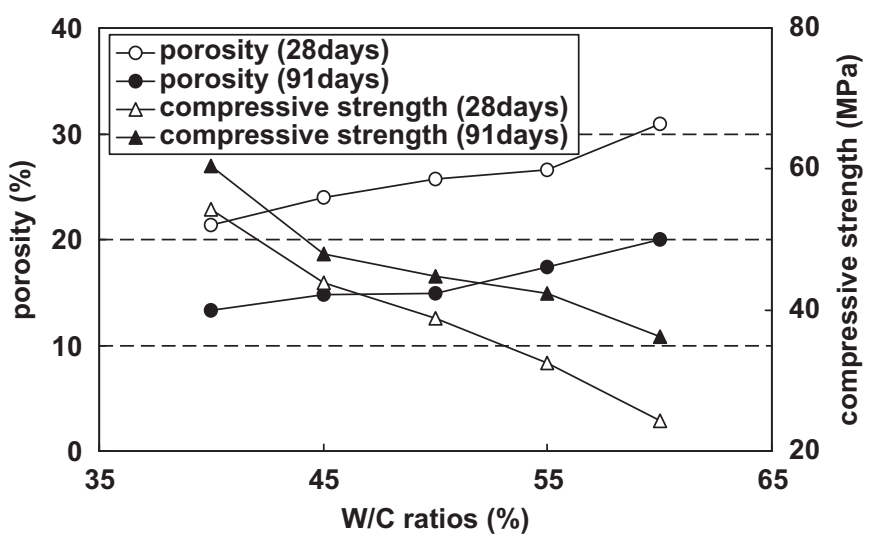

Fig. 5. Changed porosity and strength with different $\mathrm{W} / \mathrm{C}$ ratios.

constant and dependent on frequency, temperature, moisture content, chloride content, and concrete mix constituents [10,12]. Measurement equipment consists of a dielectric probe kit including an open ended coaxial probe (OECP), a network analyzer, and a laptop computer $[18,29,30]$. The OECP is a cut-off section of transmission line and the EM properties from the material are measured by placing the probe in contact with a

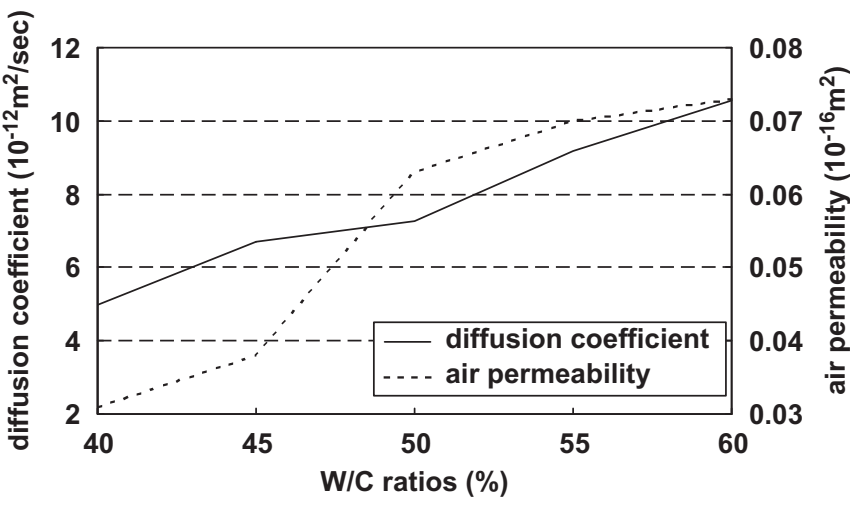

Fig. 6. Chloride diffusion coefficient and air permeability with $\mathrm{W} / \mathrm{C}$ ratios.

flat face of a solid material. It sends and receives the microwave through the probe over a frequency range from 0.2 to $20 \mathrm{GHz}$ at an interval of $0.4 \mathrm{GHz}$. The measured reflection signals are then analyzed by the software at the laptop computer for obtaining the EM properties (i.e., the dielectric constant and the conductivity). Before measuring, calibration is performed on air and water in $25^{\circ} \mathrm{C}$ temperature. The calibration results, in terms of the 
dielectric constant and the conductivity, well agree with those reported in literature $[2,18]$. In Fig. 1, experiment setup and related photo are shown.

\subsection{Saturation effect on dielectric constant and conductivity}

\subsubsection{Changes in saturation with drying process}

The cubic mortar samples $(5 \mathrm{~cm} \times 5 \mathrm{~cm} \times 5 \mathrm{~cm})$ for cement mortar are prepared for evaluation of saturation and EM measurement. They are mixed based on Table 1 and kept for 91 day for curing. After curing, the surfaces are grinded for removing the unevenness which can weaken the EM measurements. After grinding, they are exposed to $104{ }^{\circ} \mathrm{C}$ for $24 \mathrm{~h}$ and the weights in dried condition are measured. Then, they are kept in submerged condition for 2 weeks. After pickup from water, the water on its surface is removed and the weight is immediately measured. The saturation is calculated through Eq. (3) for the mortar samples exposed to room condition (temperature: $20-22^{\circ} \mathrm{C}$ and $\mathrm{RH}$ : 55-60\%)

$S=\frac{W_{a c t}-W_{d r y}}{W_{s a t}-W_{d r y}} \times 100$

where $S$ is saturation (\%), $W_{a c t}, W_{d r y}$, and $W_{\text {sat }}$ are weights in measuring, dried, and saturated condition, respectively. Tests results for evaporation and saturation are shown in Fig. 2.

a

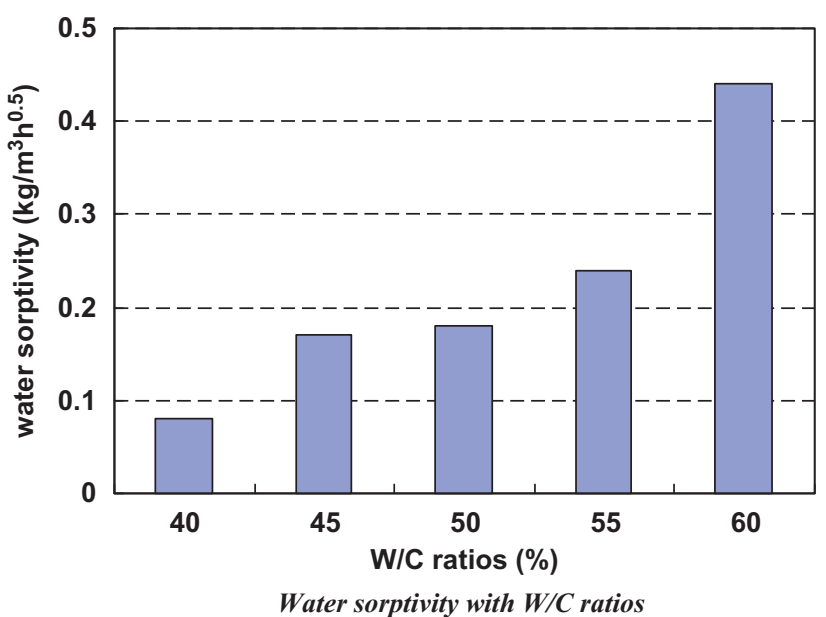

b

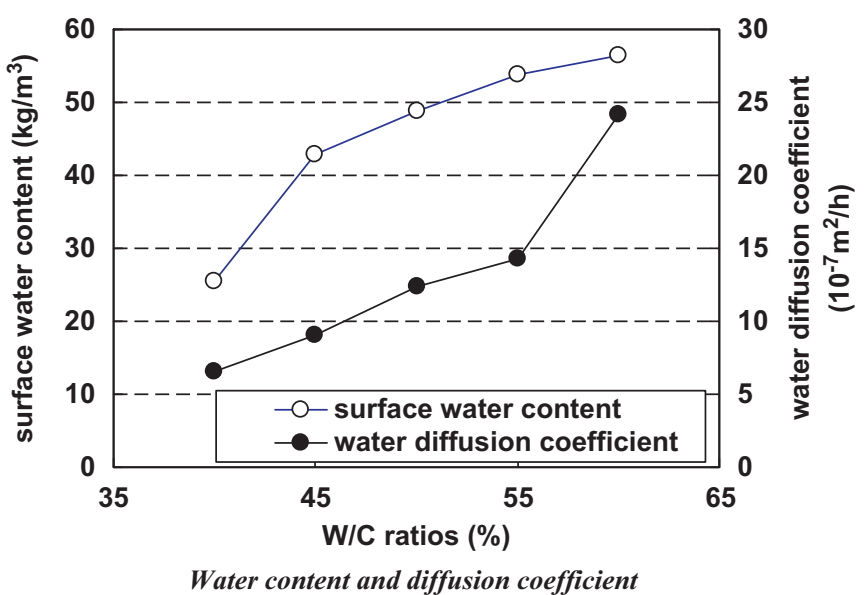

Fig. 7. Water characteristics in different $\mathrm{W} / \mathrm{C}$ ratios.
As shown in Fig. 2, the samples with higher $\mathrm{W} / \mathrm{C}$ ratios have more free water so that water loss due to evaporation more occurs. These results from water evaporation are consistent with the previous research [31], however, there are no clear differences of saturation with $\mathrm{W} / \mathrm{C}$ ratios. Since the samples with larger amount of evaporated water also have larger free water in pores, it is evaluated that ratios between them have little differences.

\subsubsection{Measurements of dielectric constant and conductivity}

For one sample, EM properties (dielectric constant and conductivity) are measured for 30 times in the frequency range of $0.2-$ $20 \mathrm{GHz}(0.4 \mathrm{GHz}$ interval $)$ and the results are averaged as one value for each measuring frequency. In order to prevent boundary disturbance, OCEP is contacted on surface from the edge at least $1 \mathrm{~cm}$. The effective depth of OCEP is reported to about $5 \mathrm{~mm}$ in concrete [32] so that the reflection of bottom boundary in this measurement can be ignored considering used sample size $(50 \mathrm{~mm})$.

As usual, dielectric constant decreases but conductivity increases with increment of frequency, and the EM properties increase rapidly with higher saturation [2,10]. In Fig. 3, representative results for EM properties with different saturation are shown.

In saturation condition, dielectric constants vary 19.3-23.2, however they decrease to $5.9-3.8$ in $20 \%$ of saturation $(0.2 \mathrm{GHz}$ frequency). In the cases of conductivity, they change from 7.1-4.8 to $0.91-1.40 \mathrm{~S} / \mathrm{m}$ with drying process $(20 \mathrm{GHz}$ of frequency). In saturated condition as shown in Fig. 3(a) and (b), the results in higher $\mathrm{W} / \mathrm{C}$ ratio are evaluated to be bigger than those in lower $\mathrm{W} / \mathrm{C}$

a

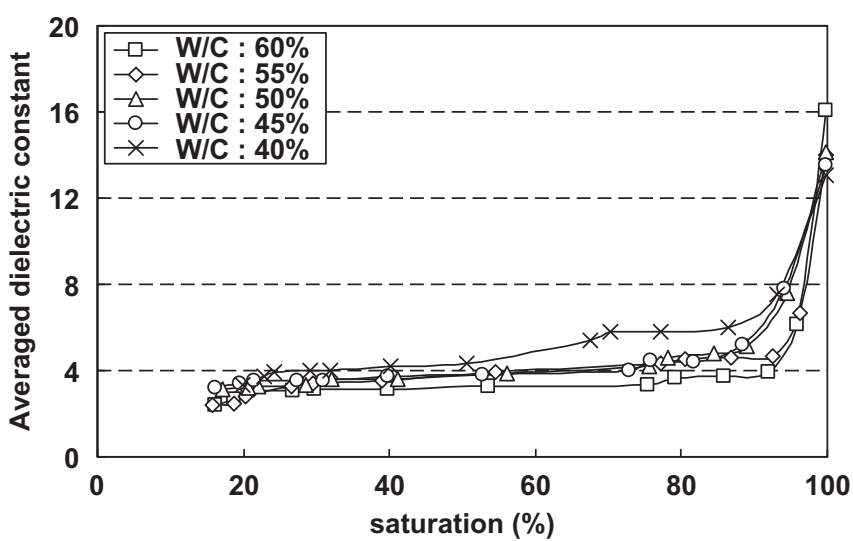

Averaged dielectric constant and saturation

b

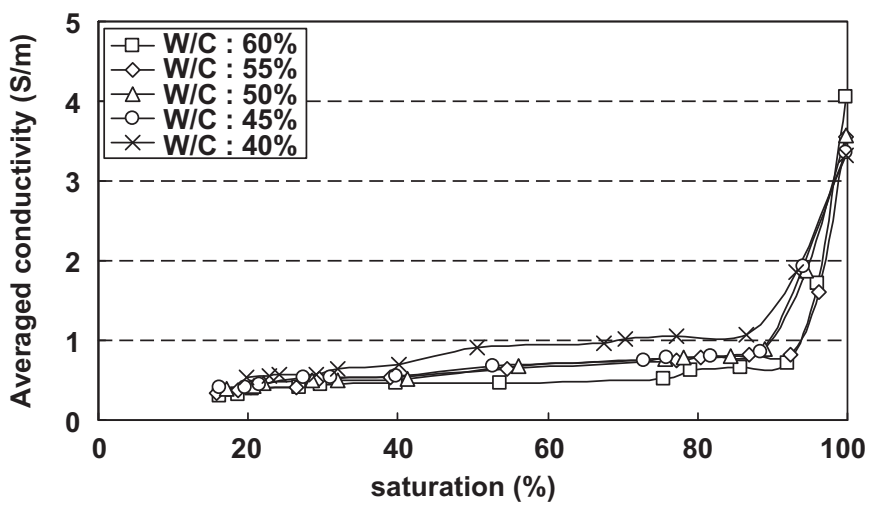

Averaged conductivity and saturation

Fig. 8. Changing average EM properties $(5-20 \mathrm{GHz})$ with saturation. 
Table 4

Relationships between averaged EM properties $(5-20 \mathrm{GHz})$ and saturation.

\begin{tabular}{|c|c|c|c|c|c|}
\hline \multicolumn{6}{|c|}{$E M=C \times(1-S)^{D}$} \\
\hline \multicolumn{3}{|c|}{ Dielectric constant } & \multicolumn{3}{|c|}{ Conductivity } \\
\hline C & $D$ & $\begin{array}{l}\text { Coefficient of } \\
\text { determination }\end{array}$ & C & $D$ & $\begin{array}{l}\text { Coefficient of } \\
\text { determination }\end{array}$ \\
\hline 9.01 & -0.17 & $R^{2}=0.95$ & 2.01 & -0.23 & $R^{2}=0.93$ \\
\hline 8.63 & -0.20 & $R^{2}=0.96$ & 1.86 & -0.27 & $R^{2}=0.92$ \\
\hline 8.77 & -0.21 & $R^{2}=0.97$ & 1.91 & -0.28 & $R^{2}=0.94$ \\
\hline 8.35 & -0.23 & $R^{2}=0.98$ & 1.81 & -0.30 & $R^{2}=0.97$ \\
\hline 8.55 & -0.27 & $R^{2}=0.98$ & 1.86 & -0.34 & $R^{2}=0.97$ \\
\hline
\end{tabular}

a

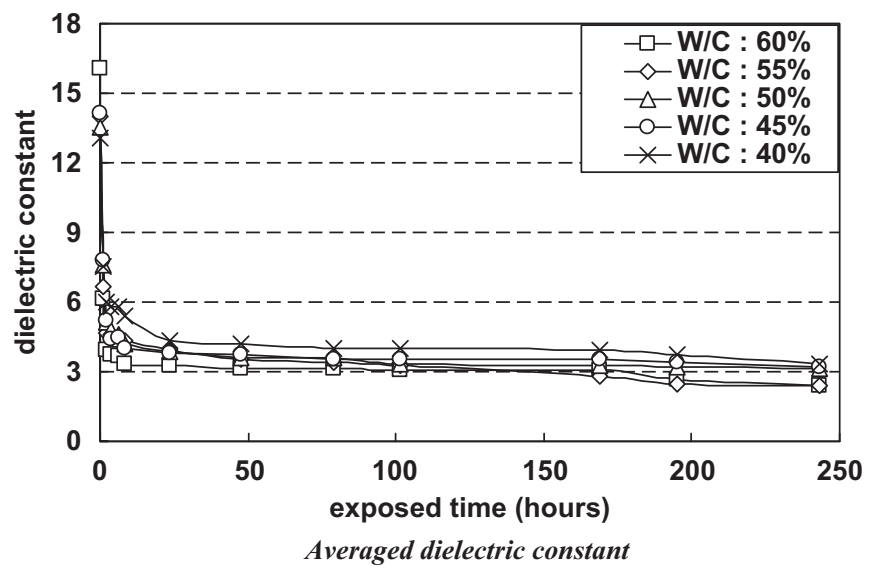

b

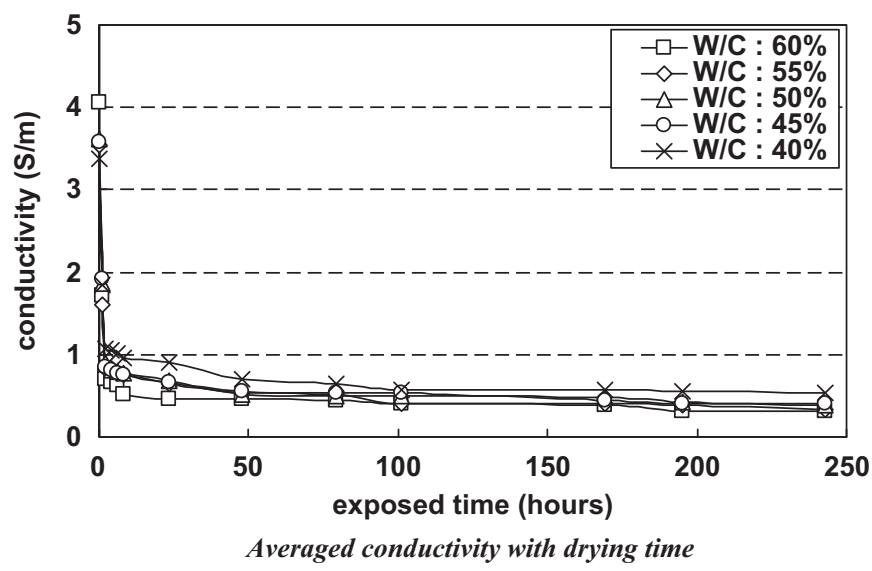

Fig. 9. Averaged EM properties in $5-20 \mathrm{GHz}$ with drying time.

ratio but this trend is changed adversely when cement mortar is dried. In the results of dielectric constant, their gradients are little changed but those in initial measurement $(0.2 \mathrm{GHz})$ are rapidly changed. As for the conductivities, the gradients are changed with $\mathrm{W} / \mathrm{C}$ ratios. The dielectric constant in air, hydrates (concrete), and water are reported to be $1,5-8$, and 81 , respectively [10]. Though a porous media like concrete is saturated, the reflected EM properties can be differently measured due to the mix proportions. When concrete with $15 \%$ of porosity is saturated, dielectric constant goes up to 2.4 times to the dried condition [10]. These results reflecting the effect of frequency range and mixture conditions are consistent with the previous studies $[18,29,30]$. The results of regression analysis can be summarized in Table 3 . The effect of saturation on dielectric constant and conductivity will be dealt with in Section 4.2 utilizing averaged data under $60 \%$ of saturation.

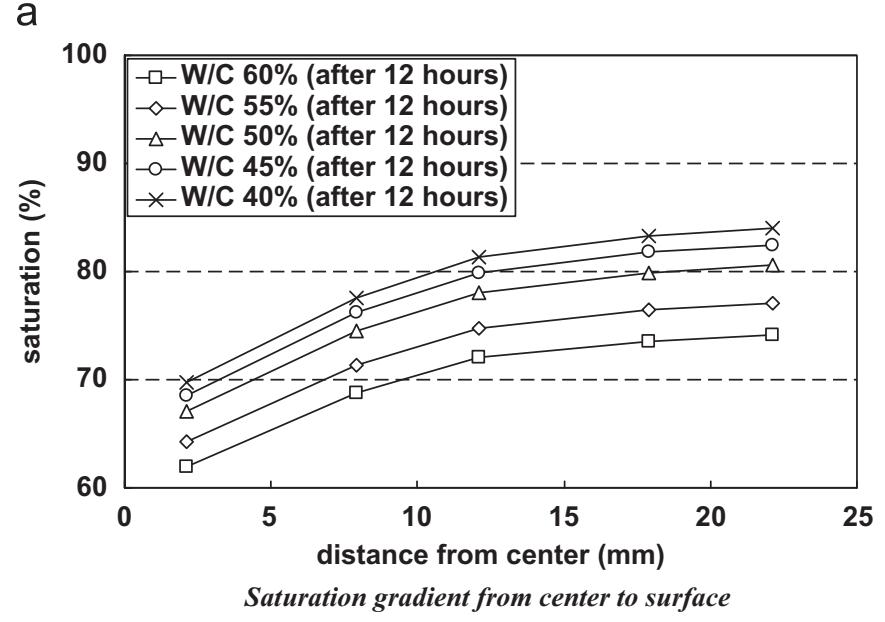

b

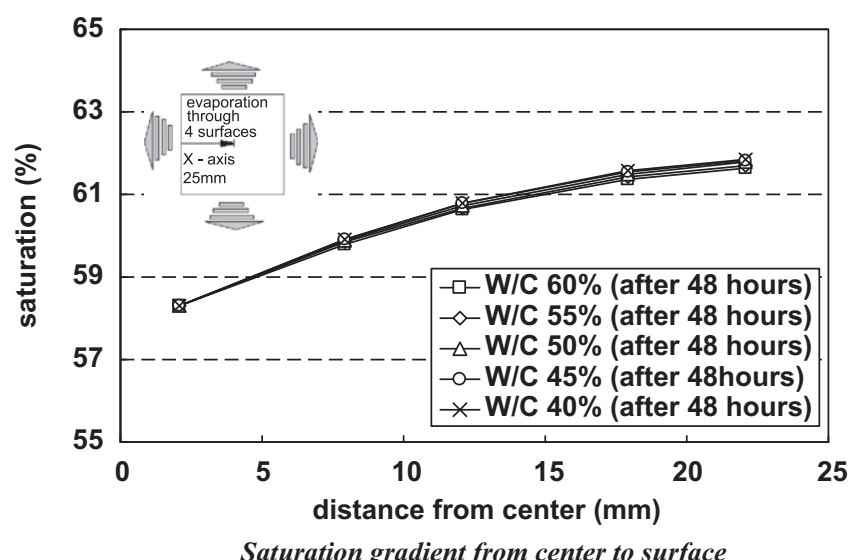

Fig. 10. Saturation in mortar with different $\mathrm{W} / \mathrm{C}$ ratios.

In derivation of average data among 30 times measurements, they have $14.7-25.8 \%$ of coefficient of variation (COV) in dielectric constant and $12.6-38.2 \%$ of COV in conductivity with $0.2-20 \mathrm{GHz}$ of frequency range. Utilizing these variables is another research interest; however, probabilistic approach for this characterization will be performed for future study.

\section{Durability test results and evaluation of EM properties}

\subsection{Durability performances through tests}

In cement mortar, porosity decreases with lower water amount and with longer curing period due to the hydration process. This is closely related to strength characteristics $[33,34]$. The results for 
porosity are shown in Fig. 4, where results at the age of 91 days are reduced to 58-64\% compared with those at the age of 28 days. Typical strength developments with different $\mathrm{W} / \mathrm{C}$ ratios are shown in Fig. 5 including the porosity changes.

In Fig. 6, the results for chloride diffusion coefficients and air permeability are shown with different $\mathrm{W} / \mathrm{C}$ ratios. Three samples in each $W / C$ ratio are tested and average value represents each case of mixture condition. They all increase in samples with higher $\mathrm{W} / \mathrm{C}$ ratios since higher porosity in mortar easily causes mass transport and capillarity.

The concrete with lower $\mathrm{W} / \mathrm{C}$ ratio has dense pore size distribution and this leads its high resistance to deterioration. The water diffusion coefficients increase with higher $\mathrm{W} / \mathrm{C}$ ratios due to the increased sorptivity affected by porosity. Test results for water diffusion are listed in Fig. 7 which includes sorptivity, surface moisture content, and water diffusion coefficient.

\subsection{Evaluation of averaged EM properties in $5-20 \mathrm{GHz}$ with different saturation}

The network analyzer used in this paper can measure dielectric constant and conductivity in frequency range of $0.2-20 \mathrm{GHz}$ continuously. In this section, data within $5-20 \mathrm{GHz}$ are averaged as one value and each average is directly compared with physical characteristics to fertilize the analysis of behavior in EM properties. Namely, averaged data in a given range can be easily plotted and compared with material properties such as $\mathrm{W} / \mathrm{C}$ ratio and durability test results, so that the relationship can be simply derived. Range for averaging data is set as $5-20 \mathrm{GHz}$ since measurements after $5 \mathrm{GHz}$ look more stable and consistent based on results in Fig. 3.

The averaged dielectric constant and conductivity in $5-20 \mathrm{GHz}$ are shown in Fig. 8 with saturation. Over $90 \%$ of saturation, both averaged dielectric constant (Fig. 8a) and conductivity (Fig. 8b) are rapidly increasing. The results of regression analysis are summarized in Table 4.

In saturated condition, samples with lower $\mathrm{W} / \mathrm{C}$ ratios show lower averaged dielectric constant and conductivity than those in dried condition but these trends are changed adversely with surface drying. Since the surface on sample with higher $\mathrm{W} / \mathrm{C}$ ratio has higher porosity, the abundant free water on surface pore causes higher EM measurements and they rapidly decrease with drying of the surface. In dried condition, the effects of larger amount of hydrates and lower porosity cause higher EM measurements in the samples with lower $\mathrm{W} / \mathrm{C}$ ratios. When saturation is reduced from $100 \%$ to $20 \%$, dielectric constant decreases to the level of $15-26 \%$. Conductivity also does to $7-$ $16 \%$ compared with results in saturated condition. The maximum reduction ratios (results in dried condition/in saturated condition) of averaged EM properties to full saturation are observed in the case of lowest $\mathrm{W} / \mathrm{C}$ ratio. The reduction ratios are evaluated to $26 \%$ (W/C: $40 \%$ ), 23\% (W/C: 45\%), 23\% (W/C: 50\%), 17\% (W/C: 55\%), and $15 \%(\mathrm{~W} / \mathrm{C}: 65 \%)$. In the case of conductivity, the reduction ratios are evaluated to $16 \%(\mathrm{~W} / \mathrm{C}: 40 \%), 11 \%(\mathrm{~W} / \mathrm{C}: 45 \%), 12 \%(\mathrm{~W} / \mathrm{C}: 50 \%)$, 9\% (W/C: $55 \%$ ), and 7\% (W/C: 65\%). Averaged EM properties in 5$20 \mathrm{GHz}$ range with drying time are shown in Fig. 9. Within $2 \mathrm{~h}$, they drop very rapidly and then show little changes afterward.

The saturation in this paper means averaged saturation in entire cubic volume but saturation gradient occurs from exterior surface to center of concrete due to different evaporation rate and exterior conditions. It is very difficult to evaluate the gradient of saturation through experiment so that moisture transport model (MTM) based on the behavior in early age concrete [33-35] is utilized to simulate the saturation gradient. In Fig. 10, saturation gradient from two-dimensional analysis is plotted after 12 and $48 \mathrm{~h}$. The one length of cubic sample is $50 \mathrm{~mm}$ so that saturation is plotted from center to outer surface ( $25 \mathrm{~mm}$ ). Fig. 10(a) shows that after $12 \mathrm{~h}$ of drying, higher saturation is evaluated in the case of lower $\mathrm{W} / \mathrm{C}$ ratios despite of similar saturation gradient for all a

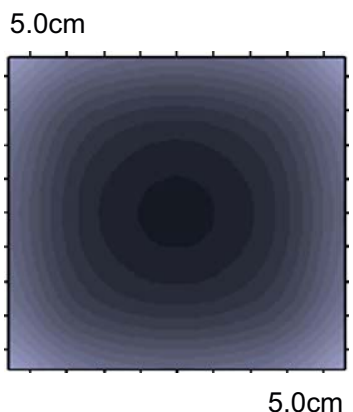

$\mathrm{W} / \mathrm{C} \mathbf{4 0} \%$

d

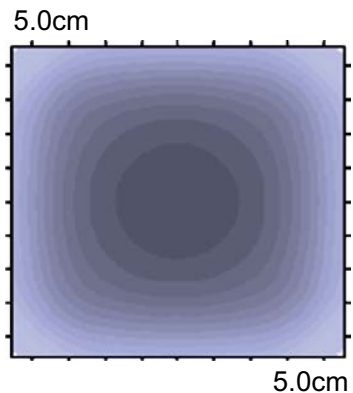

$\mathrm{W} / \mathrm{C} 55 \%$

b

$5.0 \mathrm{~cm}$

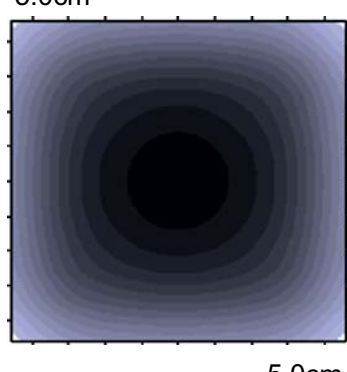

$\mathrm{W} / \mathrm{C} 45 \%$

e

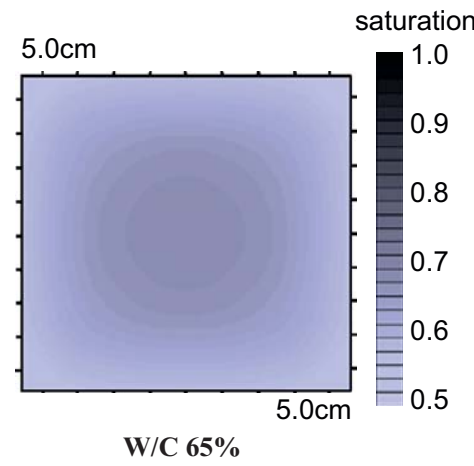

Fig. 11. Contours for saturation after $12 \mathrm{~h}$.

$5.0 \mathrm{~cm}$

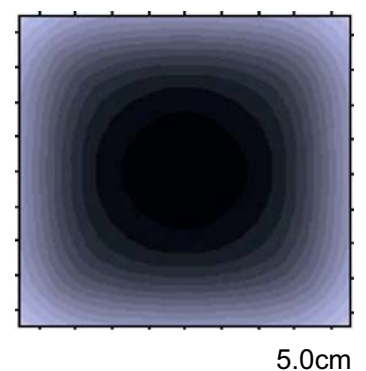

$\mathrm{W} / \mathrm{C} \mathbf{5 0 \%}$

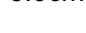


cases since small pore structures in mortar with lower $\mathrm{W} / \mathrm{C}$ ratios are capable of holding more water. After $48 \mathrm{~h}$, the results of saturation are almost same regardless of mixture conditions because of the long duration of evaporation through four surfaces. Fig. 11 show contours for samples with different $\mathrm{W} / \mathrm{C}$ ratios after $12 \mathrm{~h}$.

Effective saturation which directly affect EM properties may be different from the saturation obtained from Eq. (3) for the effective depth for this measuring equipment (OECP) is reported to only $5 \mathrm{~mm} \mathrm{[32].} \mathrm{In} \mathrm{Section} \mathrm{4.3,} \mathrm{the} \mathrm{results} \mathrm{in} \mathrm{dried} \mathrm{condition}$ (lower than $60 \%$ of saturation) are selected and used for relationship of durability characteristics. Since the size of sample is small (50 $\mathrm{mm}$ of cubic) and saturation changes within $57-63 \%$ along to depth after $48 \mathrm{~h}$, saturation from Eq. (3) is assumed as effective saturation in this study.

\subsection{Durability characterization using measured EM properties}

Through utilizing the averaged EM properties in the given frequency, the relationships for durability performance are evaluated. Among the measurements in Figs. 8 and 9, data under $60 \%$ of saturation (approximately after $24 \mathrm{~h}$ ) are selected, which show relatively stable trend. They are averaged as one value for comparison with durability characteristics. Through averaging of the selected data after $24 \mathrm{~h}$, durability characteristics and

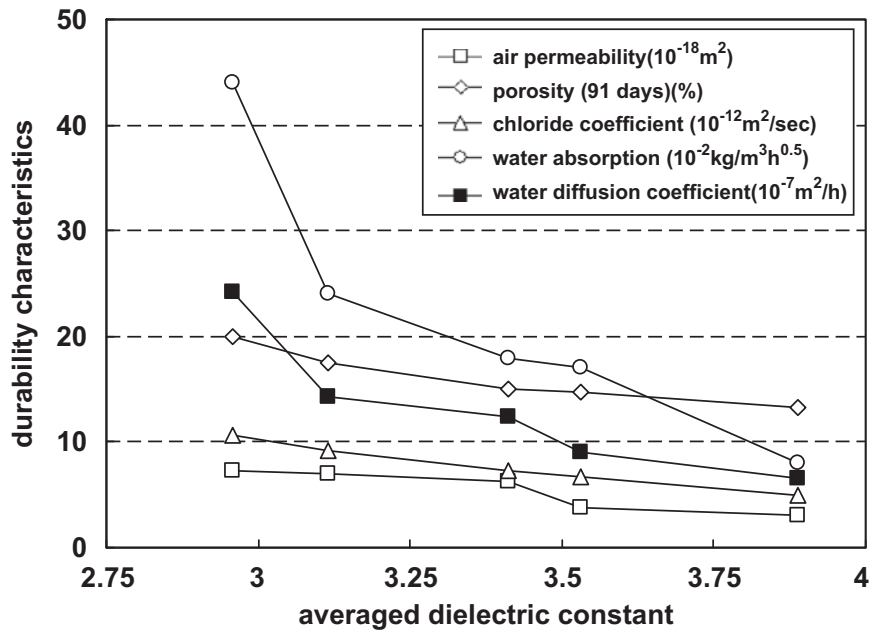

Dielectric constant and durability characteristics

b

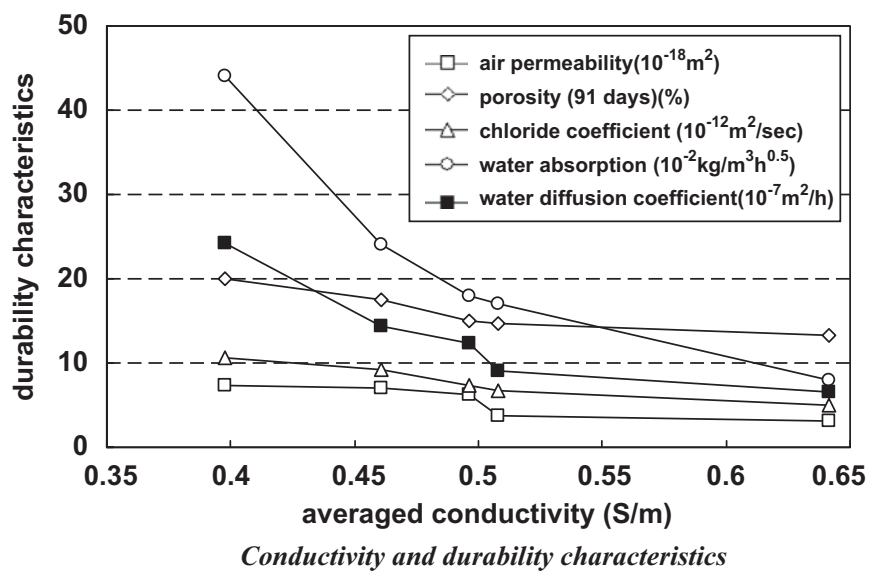

Fig. 12. Durability characteristics and averaged EM properties (after $24 \mathrm{~h}$ ). measured EM properties can be related as Fig. 12, where Fig. 12(a) and (b) show their relationships for averaged dielectric constant and conductivity, respectively.

For the evaluation of the relationships among them, each measurement can be normalized by the result from the results of $\mathrm{W} / \mathrm{C} 40 \%$. Except for strength, each measurement shows the lowest value in the case of $\mathrm{W} / \mathrm{C} 40 \%$, so that the changing ratios can be obtained through normalization. The relationships between normalized EM properties and durability characteristics are shown in Fig. 13. Fig. 13(a) and (b) show the results for normalized dielectric constant and conductivity, respectively.

When dielectric constant decreases to $76 \%$, conductivity also decreases to $62 \%$. With decrease in the normalized EM properties, the durability characteristics increase to $150 \%$ for porosity, $235 \%$ for air permeability, 210\% for chloride diffusion coefficient, 550\% for water sorptivity, and $370 \%$ for water diffusion coefficient except for strength which decreases to $60 \%$. The results of porosity, strength, air permeability, and chloride diffusion coefficient seem to have linear relationship with normalized EM properties. For durability results of water sorptivity and diffusion coefficient, exponential fitting is performed for better regression. The regression results are listed in Table 5 and this shows that durability performances can be evaluated and predicted through characterization of EM properties in the given condition. In this study, relationships from dielectric constant show better applicability for evaluation of durability performance as NDT.

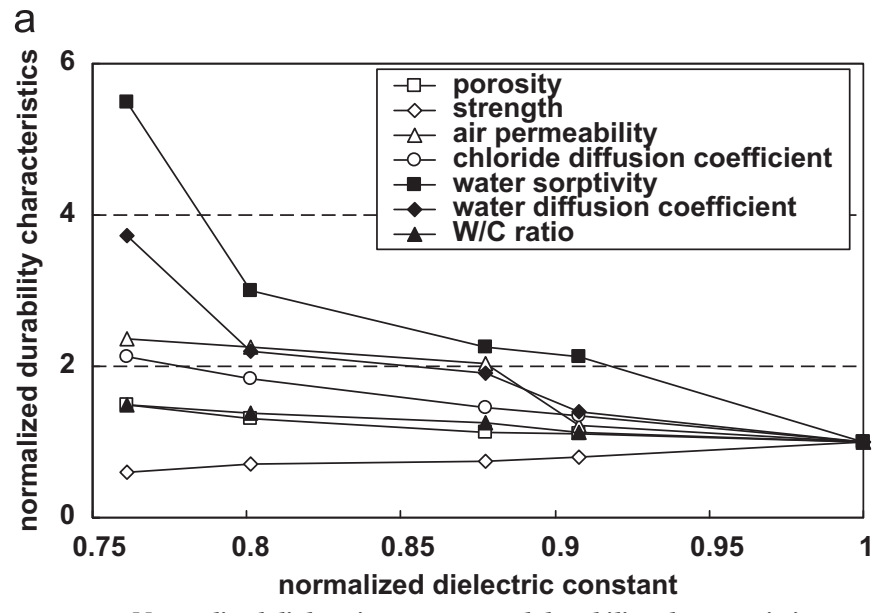

Normalized dielectric constant and durability characteristics

b

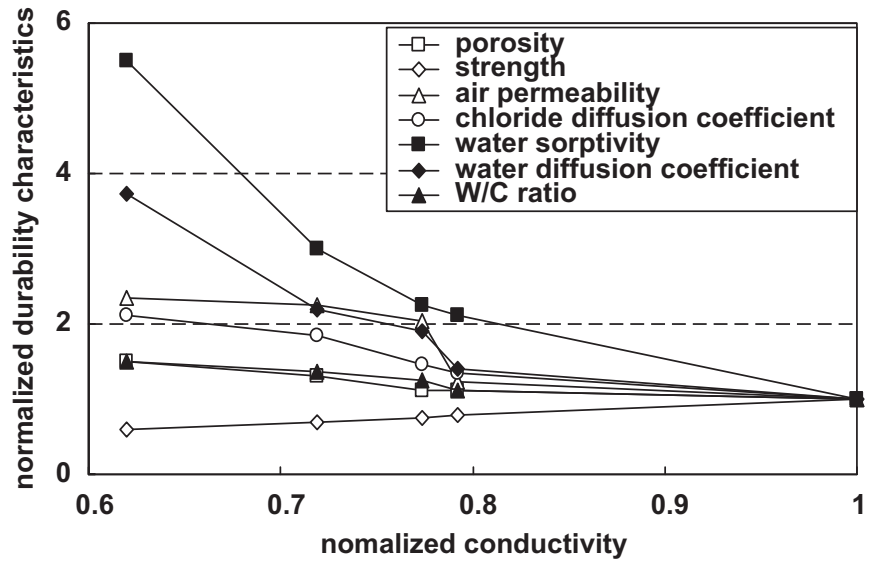

Normalized conductivity and durability characteristics

Fig. 13. Normalized EM properties and durability characteristics. 
Table 5

Results from regression analysis for the relationship between normalized EM properties and durability characteristics.

\begin{tabular}{|c|c|c|c|c|}
\hline Durability characteristics & $\begin{array}{l}\text { Relationship between normalized } \\
\text { durability characteristics }(Y) \text { and } \\
\text { dielectric constant }(D)\end{array}$ & $\begin{array}{l}\text { Coefficient of } \\
\text { determination }\end{array}$ & $\begin{array}{l}\text { Relationship between normalized } \\
\text { durability characteristics }(Y) \text { and } \\
\text { conductivity }(C)\end{array}$ & $\begin{array}{l}\text { Coefficient of } \\
\text { determination }\end{array}$ \\
\hline Normalized porosity & $Y=-2.00 D+2.95$ & $R^{2}=0.91$ & $Y=-1.27 C+2.20$ & $R^{2}=0.82$ \\
\hline Normalized strength & $Y=1.542 D-0.57$ & $R^{2}=0.94$ & $Y=1.06 C-0.05$ & $R^{2}=0.99$ \\
\hline Normalized air permeability & $Y=-6.17 D+7.14$ & $R^{2}=0.87$ & $Y=-3.86 C+4.79$ & $R^{2}=0.76$ \\
\hline $\begin{array}{l}\text { Normalized chloride diffusion } \\
\text { coefficient }\end{array}$ & $Y=-4.635 D+5.58$ & $R^{2}=0.98$ & $Y=-2.96 C+3.88$ & $R^{2}=0.91$ \\
\hline Normalized water sorptivity & $Y=1154.27 \exp (-7.14 D)$ & $R^{2}=0.92$ & $Y=157.78 \exp (-5.44 D)$ & $R^{2}=0.98$ \\
\hline $\begin{array}{l}\text { Normalized water diffusion } \\
\text { coefficient }\end{array}$ & $Y=-292.58 \exp (-3.48 D)$ & $R^{2}=0.91$ & $Y=57.78 \exp (-4.47 D)$ & $R^{2}=0.94$ \\
\hline
\end{tabular}

In the previous researches [8,9,36], the changing behaviors of EM properties have been studied for the cement materials under hydration process. Those studies are only for the characterization of EM properties under hydration which cannot provide the quantitative information on physical parameters of durability characteristics which are significantly changed with mixture conditions. In the research [37], dielectric constant using GPR was measured for two different concrete samples (W/C: $61 \%$ and $48 \%$ ) considering water content. Durability characteristics like porosity and permeability were measured at 28 and 90 days and linear relationship between dielectric constant and water content was achieved. However, the maximum range of water content in the Ref. [37] was $11.0 \%$ (87.9\% of saturation) and significant increase in EM measurements was expected if it would have more saturated condition. The concrete with lower $\mathrm{W} / \mathrm{C}$ ratios and long age showed lower porosity and air permeability. These results are consistent with the test results from this study.

EM properties have very different behaviors according to the porosity and saturation in cement-based materials. However, a controlled relative humidity condition, the effect of surface saturation can be assumed to be constant. In this condition, EM properties are changing with the porosity which holds air and this can be utilized for evaluation of durability performances in cement mortar, since they are greatly dependent on porosity. This is an experimental approach with OECP for the laboratorial test but it will be improved with consideration for an effect of coarse aggregate in concrete and core effect from field application.

\section{Concluding remarks}

The conclusions on characterization of electromagnetic properties for durability performance and saturation in hardened cement mortar are as follows:

(1) Dielectric constant and conductivity are measured for 30 times and results within $5-20 \mathrm{GHz}$ of frequency range are averaged one value which is plotted with saturation. Results in mortar samples with higher porosity (W/C: 60\%) show higher averaged EM properties in saturated condition due to the larger amount of free water in pores on surface. However, with drying process those with lower porosity (W/C: $40 \%$ ) show higher averaged EM properties. Before $90 \%$ of saturation, averaged dielectric constant and conductivity in all the cases rapidly decrease.

(2) In order to evaluate the changing ratio of EM properties, results under $60 \%$ of saturation are selected among the measured dielectric constant and conductivity within 5$20 \mathrm{GHz}$, which shows relatively stable. Then normalization through the results (in the case of W/C: $40 \%$ ) which show the highest durability performance is carried out. When normalized dielectric constant and conductivity decrease to $76 \%$ and
$62 \%$, respectively, durability characteristics increase to $150 \%$ of porosity, $235 \%$ of air permeability, $210 \%$ of chloride diffusion coefficient, $550 \%$ of sorptivity and $370 \%$ of water diffusion coefficient. But compressive strength is reduced to $60 \%$.

(3) The relationships for durability characteristics utilizing normalized EM properties are derived through regression analysis. This study can provide the valuable information on the characterization of durability performance in cement mortar through the measured dielectric constant and conductivity.

\section{Acknowledgements}

This work was supported by the Korea Research Foundation Grant funded by the Korean Government (MOEHRD, Basic Research Promotion Fund-2008-D00266).

\section{References}

[1] Glanvile J, Nevile A. Prediction of concrete durability. In: Proceedings of the STATS 21st anniversary conference, E\&FN SPON, 1995. p. 16-36.

[2] Rhim HC, Buyukozturk O. Electromagnetic properties of concrete at microwave frequency range. ACI Mater J 1998;92:262-71.

[3] Soutsos MN, Bungey JH, Millard SG, Shaw MR, Patterson A. Dielectric properties of concrete and their influence on radar testing. NDTE Int 2000;34: 419-25.

[4] McCarter WJ, Starrs G, Chrisp TM. Immittance spectra for Portland cement/fly ash-based binders during early hydration. Cem Concr Res 1999;29: 377-87.

[5] McCarter WJ, Starrs G, Chrisp TM. The complex impedance response of fly-ash cement revisited. Cem Concr Res 2004;34:1837-43.

[6] McCarter WJ, Chrisp TM, Starrs G, Blewett J. Characterization and monitoring of cement-based systems using intrinsic electrical property measurements. Cem Concr Res 2003;33:197-206.

[7] Wittmann FH. Micro wave absorption of hardened cement paste. Cem Concr Res 1975;5:63-71.

[8] Zhang W, Ding XZ, Lim TH, Ong CK, Tan BTG, Yang J. Microwave study of hydration of slag cement blends in early period. Cem Concr Res 1995;25:1086-94.

[9] Taylor MA, Arulanandan K. Relationships between electrical and physical properties of cement pastes. Cem Concr Res 1974;4:881-97.

[10] Halabe UB, Sotoodehnia A, Maser KR, Kausel EA. Modeling the electromagnetic properties of concrete. ACI Mater J 1993;90:552-63.

[11] Feng S, Sen PN. Geometrical model of conductive and dielectric properties of partially saturated rocks. J Appl Phys 1985;58:3236-43.

[12] Halabe UB. Condition assessment of reinforced concrete structures using electromagnetic waves. Doctoral thesis, Department of Civil Engineering, MIT, Cambridge, 1990.

[13] Roddis WMK Concrete bridge deck assessment using thermography and radar. Master's thesis, Department of Civil Engineering, MIT, Cambridge; 1987.

[14] Chrisp TM, McCarter WJ, Starrs G, Basheer PAM, Blewett J. Depth-related variation in conductivity to study cover zone concrete during wetting and drying. Cem Concr Res 2002;24:415-26.

[15] Rhim HC. Condition monitoring of deteriorating concrete dams using radar Cem Concr Res 2001;31:363-73.

[16] Feng MQ, Kim YJ, De Flaviis FD. Use of microwaves for damage detection of FRP-wrapped concrete structures. J Eng Mech (ASCE) 2001;128:172-83. 
[17] Kim YJ, Jofre L, De Flaviis FD, Feng MQ. Microwave reflection tomography array for damage detection of concrete structures. In: Proceedings of the IEEE MTT-S international microwave symposium digest, Seattle, WA, 2002.

[18] Rhim HC, Kim YJ, Feng MQ, Woo SK, Song YC. Measurements of electromagnetic properties of concrete and fiber reinforced polymer for nondestructive testing. In: US-Korea joint seminar/workshop on smart structures technologies, Sheraton Walker Hill Hotel, Seoul, Korea, 2004.

[19] Ishida T, Chaube RP, Maekawa K. Modeling of pore content in concrete under generic drying wetting conditions. Concr Libr JSCE 1996;18(1):113-8.

[20] Song HW, Kwon SJ. Permeability characteristics of carbonated concrete considering capillary pore structure. Cem Concr Res 2007;37:909-15.

[21] Kumar R, Bhattacharjee B. Study on some factors affecting the results in the use of MIP method in concrete research. Cem Concr Res 2003;33:417-24.

[22] Korean Standard, Method of test for compressive strength of concrete-KSF 2405, 2005.

[23] Kwon SJ, Na UJ, Park SS, Jung SH. Service life prediction of concrete wharves with early-aged crack: probabilistic approach for chloride diffusion. Struct Saf 2009;31:75-83.

[24] Tang L, Joost G. On the mathematics of time-dependent apparent chloride diffusion coefficient in concrete. Cem Concr Res 2007;37:589-95.

[25] NORDTEST. Chloride migration coefficient from non-steady-state migration experiments, NT BUILD 492, 1999.

[26] Soh HS, Soh YS. The relationship between the compressive strength and air permeability of concrete. J Archit Inst Korea Struct Constr 2000;16:107-12 [in Korean].

[27] Neithalath N. Analysis of moisture transport in mortar and concrete using sorption-diffusion approach. ACI Mater J 2006;103:209-17.
[28] Korea Standard, Determination of the water absorption coefficient of building materials, KS F 2609-1712, 2003.

[29] Kwon SJ, Feng MQ, Park TW, Na UJ. An experimental study on evaluation of compressive strength in cement mortar using averaged electromagnetic properties. Int J Concr Struct Mater 2009;3:25-32.

[30] Kwon SJ, Feng MQ, Na UJ. An experimental study on electromagnetic properties in chloride-contaminated cement mortar, ASCE, International Committee, Los Angeles Section. In: 5th international engineering and construction, conference (IECC'5), August 27-29, 2008. p. 673-80.

[31] Song HW, Cho HJ, Park SS, Byun KJ, Maekawa K. Early-age cracking resistance evaluation of concrete structure. Concr Sci Eng 2001;3:62-72.

[32] Rhim HC, Jeong SH. Measurement of electromagnetic properties of concrete for nondestructive testing. J Kor Concr Inst 2000;12:115-23 [in Korean].

[33] Mabrouk R, Ishida T, Maekawa K. A unified solidification model of hardening concrete composite for predicting the young age behavior of concrete. Cem Concr Compos 2004;26(5):453-61.

[34] Maekawa K, Chaube R, Kishi T. Modeling of concrete performance: hydration, microstructure formation and mass transport. London; New York: Routledge; 1999.

[35] Ishida T, Chaube RP, Maekawa K. Modeling of pore content in concrete under generic drying wetting conditions. Concr Libr JSCE 1996;18:113-8.

[36] Gorur K, Smit MK, Wittmann FH. Microwave study of hydrating cement paste at early age. Cem Concr Res 1982;12:447-54.

[37] Derobert X, laquinta J, Klysz G, Balayssac JP. Use of capacitive and GPR techniques for the non-destructive evaluation of cover concrete. NDTE Int 2008;41:44-52. 